\title{
Endoscopic Resection for Undifferentiated-Type Early Gastric Cancer
}

\author{
Yorimasa Yamamoto et al.* \\ Division of Gastroenterology, Cancer Institute Hospital \\ Japan
}

\section{Introduction}

Currently, endoscopic resection (ER) is the standard treatment for early gastric cancer (EGC), not only in Japan but also in other parts of the world. (Gotoda T et al., 2006)

A new endoscopic resection procedure, called endoscopic submucosal dissection (ESD), allows the direct dissection of the submucosa and has made en bloc resection of large intramucosal or ulcerated lesions feasible. However, at present, the indications for use of ER are limited to EGC without lymph node metastasis.

Gotoda et al. studied surgically resected specimens from EGC patients and decided upon the following four indication criteria for endoscopic resection of EGC without lymph node metastasis. (Gotoda T et al.,2000) (Fig 1)

1. differentiated intramucosal cancer without ulceration, regardless of size

2. differentiated intramucosal cancer with ulceration, $30 \mathrm{~mm}$ or less in size

3. differentiated minute submucosal penetrative cancer (SM1), 30mm or less in size

4. undifferentiated intramucosal cancer without ulceration, $20 \mathrm{~mm}$ or less in size

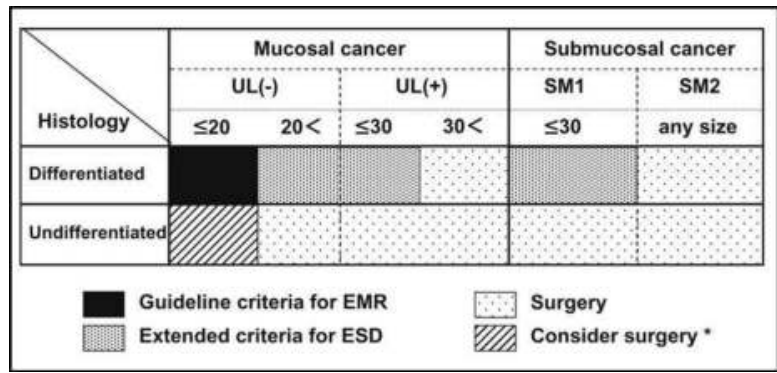

Fig. 1. Extended criteria for endoscopic resection (Tumor size is shown in millimeters). EMR: Endoscopic mucosal resecton. ESD: Endoscopic submucosal dissection.

UL: ulcerative findings. SM: submucosal

\footnotetext{
*Junko Fujisaki ${ }^{1}$, Toshiaki Hirasawa ${ }^{1}$, Takanori Suganuma1 ${ }^{1}$ Masami Omae ${ }^{1}$, Kazuhisa Okada $^{1}$, Susumu Sawada ${ }^{2}$, Akiyoshi Ishiyama ${ }^{1}$, Tomohiro Tuchida ${ }^{1}$, Etuo Hoshino ${ }^{1}$, Hiroshi Takahashi ${ }^{2}$ and Masahiro Igarashi ${ }^{1}$

1 Division of Gastroenterology, Cancer Institute Hospital, Japan,

2 Department of Gastroenterology, Showa University Fujigaoka Hospital, Japan.
} 
Expansion of the indications for ER to include undifferentiated-type EGC is not widely accepted at this time because undifferentiated-type EGC has been associated with higher rates of lymph node metastasis than has differentiated-type EGC. (Sano T et al.,1992 ; Yamao T et al.,1996)

Furthermore, it is sometimes difficult to delineate carcinomatous areas in cases where undifferentiated-type EGC is not exposed on the mucosa surface. (Ninomiya Y et al.,2000)

As a result, successful endoscopic resection is reportedly less common in patients with undifferentiated-type EGC compared to those with differentiated EGC. (Miyata M et al.,2000) To avoid invasive surgery, and thereby optimize the patient' s quality of life, it is important to expand the ER indication to include undifferentiated-type EGC in patients at a very low risk of lymph node metastasis.

Recently, several studies for undifferentiated-type EGC treated by endoscopic resection have been reported from different institutions. (Kim JH et al., 2009 ; Kang HY et al.,2010 ; Yamamoto $\mathrm{Y}$ et al.,2010) According to these reports, endoscopic resection for undifferentiated-type EGC was technically feasible and might be considered an alternative treatment modality.

In this review, we described the state of diagnostic and therapeutic endoscopy for undifferentiated-type EGC.

\section{Undifferentiated-type EGC without lymph node metastasis}

Because ER involves only local treatment without lymph node dissection, as a rule, it is performed only if lymph node metastases are not present.

In the study by Gotoda et al., the criteria for undifferentiated-type EGC without lymph node metastasis was intramucosal cancer without ulceration and a diameter of no more than 20mm (expanded-indication lesion). (Gotoda T et al.,2000)

However, this category of tumor was diagnosed in only 141 cases, and the $95 \%$ confidence interval for the frequency of positive lymph node metastases was $0-2.6 \%$. This corresponds to a 5-year survival rate worse than the $99 \%$ associated with surgically resected intramucosal gastric carcinoma. Therefore, expansion of the indications for ER to include undifferentiated-type EGC was not widely accepted at that time.

Recently, Hirasawa et al. added to Gotoda's findings, by reporting on cases of undifferentiated-type EGC resected at their institutions over the past 9 years; they reported the lymph node metastasis rate and the validity of ER for undifferentiated-type EGC. (Hirasawa T et al,.2009) In the study, the number of expanded-indication lesion reached 310, and no lymph node metastasis was found in any of these cases. (Table 1)

\begin{tabular}{lc}
\hline Tumor size & LNM rate $(\%)$; UL(-) and LVI(-) \\
\hline$\leqq 10 \mathrm{~mm}$ & $0.0(0 / 105)$ \\
$11-20 \mathrm{~mm}$ & $0.0(0 / 205)$ \\
$21-30 \mathrm{~mm}$ & $1.9(3 / 162)$ \\
$\geqq 31 \mathrm{~mm}$ & $5.2(13 / 249)$ \\
Total & $2.2(16 / 721)$ \\
\hline
\end{tabular}

Table 1. Lymph node metastasis by tumor size without UL and LVI in undifferentiated-type intramucosal EGC LNM: lymph node metastasis LVI: lymphatic-vascular capillary involvement UL: ulcerative findings 
Thus, the $95 \%$ confidence interval decreased to $0-0.96 \%$, with an upper limit of $1 \%$ or less. Therefore, it is suggested that the expanded-indication lesion of undifferentiated-type EGC could be considered suitable for curative ER due to the negligible risk of lymph node metastasis.

Several studies have proved that none of the cases of surgically resected expandedindication lesions was associated with positive lymph nodes. (Ha TK et al.,2008; Li C et al.,2008 ; Li H et al.,2008 ; Ye BD et al.,2008 ; Kunisaki C et al.,2009 ; Li H et al.,2010)

However, even if the lesion met the criteria for expanded-indication lesion pathologically, in the previous study, some lesions with lymph node metastasis were reported. In three studies of surgically resected undifferentiated-type EGC that were $20 \mathrm{~mm}$ or smaller in diameter and had neither ulceration nor lymphovascular invasion, a few were found to have metastasized. Lymph node metastases were found by Abe et al. in two cases with 10mm or 12-mm lesions, (Abe $\mathrm{N}$ et al.,2004) by Nasu et al. in one case with a 13-mm lesion, (Nasu J et al.,2006) and by Park et al. in one case with a 17-mm lesion. (Park YD et al.,2008)

Even though the expanded-indication lesions of undifferentiated-type EGC have a very low risk of lymph node metastasis according to the report of Hirasawa et al, we should remain aware of the fact that a few of the expanded-indication lesion cases may have lymph node metastases.

What kind of mechanism would permit such a lesion to metastasize to the lymph nodes?

In normal gastric mucosa, lymphatic vessels are not found in the upper and middle part of the lamina propria; they exist in the deep lamina propria adjacent to the muscularis mucosa.

These morphologic findings correlate with clinicopathological observations on early gastric cancer. The particularly low incidence of lymph node metastases in the subtype of early gastric cancer that remains confined to the mucosa may be explained by the rarity of lymph capillaries in the mucosa. (Lehnert T et al.,1985 ; Listrom MB et al.,1987)

Sako et al. studied the distribution of lymphatic vessels in the gastric wall by immunostaining for D2-40. (Sako A et al., 2006) The densest distribution of lymphatic vessels was seen in the muscularis mucosa layer. If cancer cells reached the muscularis mucosa layer, they might have the greatest chance of invading the lymphatic vessels.

The morphological detection of intralymphatic tumor cells might be more difficult in undifferentiated-type EGC than differentiated-type EGC. The reason for this was presumed to be that undifferentiated-type EGC are often associated with a loss of glandular formation in the gastric wall, and the cancer cells may be more scattered in the lymphatic vessels.

Therefore, it is possible that if undifferentiated-type EGC reached the deep layer of the mucosa or the muscularis mucosa, the cancer cell could metastasize to the lymph node without invading the general lymphatic system.

However, it is noteworthy that no case with expanded-indication lesions of undifferentiated-type EGC less than $10 \mathrm{~mm}$ in diameter had lymph node metastases. ER is therefore indicated in such lesions.

We suggest that ER should be used for the treatment of expanded-indication lesions of undifferentiated-type EGC in order to avoid unnecessary invasive surgery and optimize the quality of life. 


\section{The characteristics of expanded-indication lesion of undifferentiated-type EGC}

Most patients with EGC treatable using ER have presented with no cancer related symptom: they have undergone an endoscopy because of symptoms of gastritis or esophagitis, and the cancers have been diagnosed incidentally.

Because an undifferentiated-type EGC indicated for ER has a diameter less than $20 \mathrm{~mm}$, it is important for an endoscopist to fully understand the endoscopic finding of such a lesion.

We performed a retrospective analysis of 60 patients who had histologically expandedindication lesions of undifferentiated-type EGC in whom an ESD was performed at the Cancer Institute Hospital between March 2005 and August 2009. The patient characteristics and the endoscopic findings are shown in Table 2.

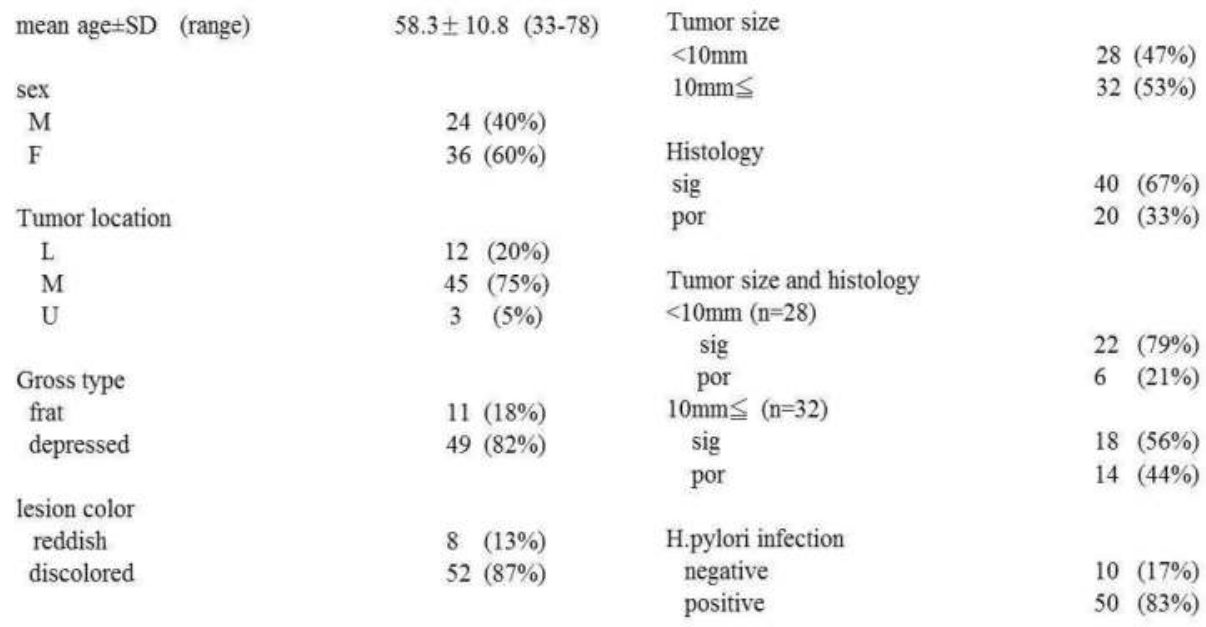

Table 2. Patient characteristics $(\mathrm{n}=60)$

The mean age of the patients was $58.3 \pm 10.8$ years (range, $33-81$ years), and number of male and female patients was $24(40 \%)$ and $36(60 \%)$ respectively.

The locations of lesions were as follows: lower third of stomach in 12 cases (20\%); middle third in 45 cases (75\%); upper third in 3 cases (5\%).

Regarding the gross type, 11 lesions (18\%) were flat, and 49(82\%) were depressed, and regarding the tumor color, $52(87 \%)$ were discolored, and $8(13 \%)$ were reddish. Twenty-eight lesions (47\%) were less than $10 \mathrm{~mm}$ in diameter, and $32(53 \%)$ were larger than $10 \mathrm{~mm}$.

Regarding the histological findings, 40(67\%) were signet ring cell carcinoma, and 20(33\%) were poorly-differentiated adenocarcinoma.

Regarding the association between tumor size and histological finding, 22 of 28 lesions $(79 \%)$ less than $10 \mathrm{~mm}$ in diameter were histologically signet ring cell carcinoma, 18 of 32 lesions $(56 \%)$ greater than $10 \mathrm{~mm}$ in diameter were poorly-differentiated adenocarcinoma; lesions greater than $10 \mathrm{~mm}$ in diameter frequently showed poorly-differentiated adenocarcinoma. 
With respect to Helicobacter pylori (HP) infection, 17 of 60 patients (17\%) showed no HP infection and no atrophic change in the gastric mucosa, these 17 patients were negative for serum HP antibody and serum pepsinogen; undifferentiated-type EGC was found in the patients who were negative for HP infection.

In summary, undifferentiated-type EGC tended to be found more frequently in females than in males, located in the middle third of the stomach, be 'discolored' in appearance, and was most frequently of the depressed type. (Fig 2)
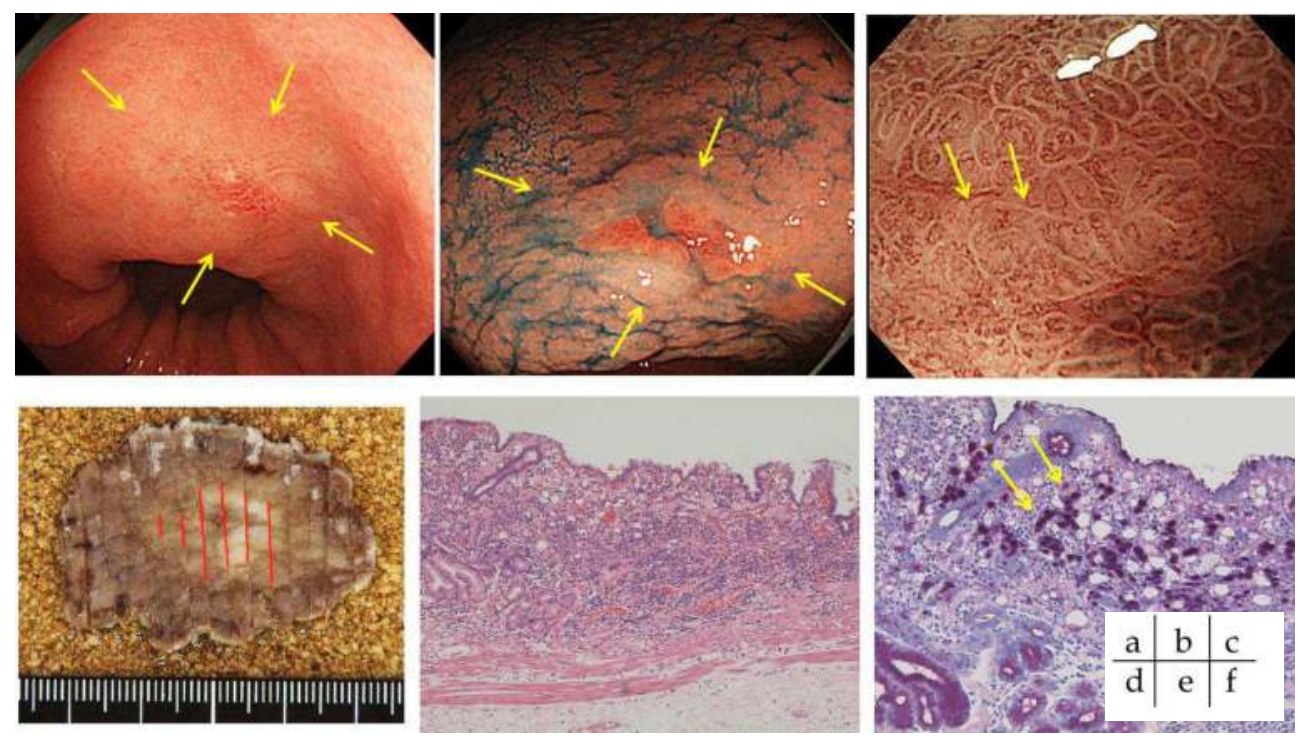

a: Routine observation: A discolored area with biopsy scar in the central was located on the lower-body lesser curvature.. (yellow arrows)

b: Indigo carmine spraying: Dye spraying revealed a discolored lesion with depression. (yellow arrows).

c: Narrow band imaging with magnifying view : NBI showed irregular vascular pattern in the depressed lesion. (yellow arrows)

d: Resected specimen: specimen size $28 \times 23 \mathrm{~mm}$, tumor size $13 \times 9 \mathrm{~mm}$, type 0 -IIc, sig, UL(-), pM, ly0, v0, $\mathrm{LM}(-), \mathrm{VM}(-)$.

e: HE staining: Tubular structure in the lesion was not recognized.

f: PAS staining: Signet-ring cells with PAS staining positive were observed in the middle layer of the mucosa.(yellow arrows)

Fig. 2. Undifferentiated EGC met expand-indication criteria for ESD.

In the development of gastric cancer, it was very interesting that undifferentiated-type EGC was even found in the patients with no evidence of HP infection. (Fig 3)

In a depressed-type EGC, encroachment of the border is one important malignant sign to look for in endoscopic findings. (Oohara et al.,1984; Fujii T et al.,1994) However, Takahashi et al. reported that encroachment of the border was found in only $20 \%$ patients with undifferentiated-type EGC with diameters less than 10mm. (Takahashi H et al.,2009)

To diagnose undifferentiated-type EGC treatable by ER, an endoscopist should take care when performing an endoscopic examination in order not to overlook a depressed and discolored lesion with no encroachment of the border. 

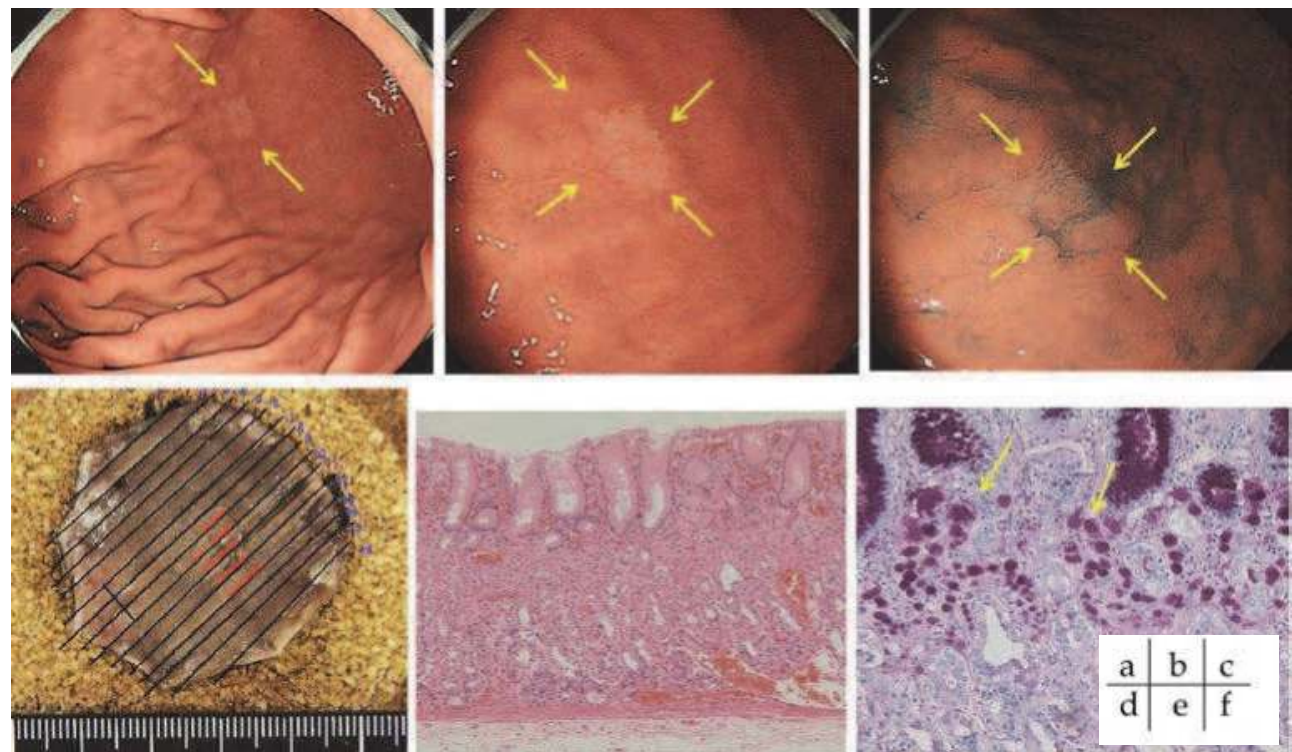

a: Routine observation: A discolored area was located on the lower-body anterior wall. (yellow arrows) This patient had not H.pylori infection

b: Closed view: The border of discolored area was clearly distinguished from the adjacent mucosa.

c: Indigo carmine spraying: Dye spraying revealed a discolored lesion without depression. (yellow arrows). The macroscopic appearance suggested type 0 -IIb early gastric cancer.

d: Resected specimen: specimen size $28 \times 23 \mathrm{~mm}$, tumor size $13 \times 9 \mathrm{~mm}$ (red line), type 0 -IIc, sig, UL(-), pM, ly0, v0, LM(-), VM(-).

e: HE staining: Tubular structure in the middle layer of the lesion was not recognized.

f: PAS staining: Signet-ring cells with PAS staining positive were observed in the middle layer of the mucosa. (yellow arrows)

Fig. 3. A case of undifferentiated EGC without H.pylori infection.

\section{Diagnosis of tumor margin and narrow band imaging for undifferentiated- type EGC}

Narrow band imaging (NBI) is a new electronic endoscopy system ideally suited to the observation of surface structures, including capillaries. With NBI, short wavelength light radiated through a narrow band filter is strongly absorbed by hemoglobin, thereby allowing surface vascular structures to be distinctly visualized. (Gono K et al.,2004)

The NBI-magnifying endoscopy is capable of predicting the histological characteristics of gastric cancer lesions in not only well-differentiated-type ECG but also in undifferentiatedtype.

Nakayoshi et al. reported that microvascular structures can be observed using the NBI magnifying endoscopy, with a fine network pattern visible in well-differentiated-type EGC, and, in contrast, a corkscrew pattern in undifferentiated-type EGC. (Nakayoshi T et al.,2004) Taken together, these findings suggest that, if a discolored depressed lesion without encroachment found by conventional endoscopy showed a corkscrew pattern by NBI, the lesion is probably undifferentiated-type EGC. 
It is well known that it is more difficult to determine the lesion margin in undifferentiatedtype EGC than in well-differentiated-type. In some cases of undifferentiated-type EGC, the lesion margin estimated macroscopically with the naked eye differs from that determined by pathology. (Ninomiya et al.,2000)

This difference occurs when the tumor extends along the proliferative zone in the middle layer of the mucosa, leaving normal ducts covering the superficial mucosa. When this extension of cancer cells along the proliferative zone occurs, it is difficult to diagnosis the area of the lesion, even using NBI-magnifying endoscopy. To achieve a more accurate diagnosis, circumferential biopsies of the lesion should be done in all cases of undifferentiated-type EGC.

Recently, we have reported that the width of the proliferative zone in 40 cases of expanded-

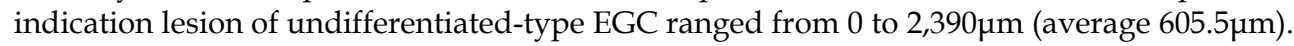
(Sawada S et al.,2010) (Fig.4)

In no cases was the width of the proliferative zone over $3 \mathrm{~mm}$. (Table 3 )

From these results, we recommend that markings around a lesion should be placed $5 \mathrm{~mm}$ beyond the endoscopically determined lesion margin, and mucosal incisions should be made outside these markings for ER of undifferentiated-type EGC.

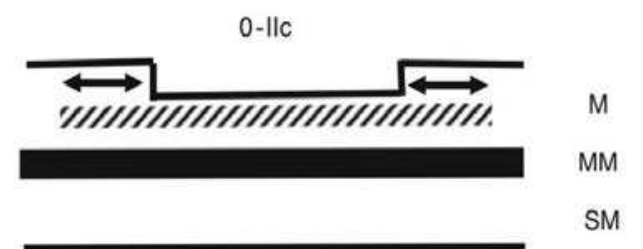

Width of proliferative zone

M : mucosa MM : musucularis mucosa SM : submucosa

Fig. 4. Width of proliferative zone

\begin{tabular}{ll}
\hline $0-1,000 \mu \mathrm{m}$ & $28(70)$ \\
$1,001-2,000 \mu \mathrm{m}$ & $11(27.5)$ \\
$2,001-3,000 \mu \mathrm{m}$ & $1 \quad(2.5)$ \\
Total & $40(\%)$ \\
\hline $\mathrm{n}=40$, mean $=605.5 \mu \mathrm{m}$ &
\end{tabular}

Table 3. Width of proliferative zone (0- II c type undifferentiated-type intramucosal EGC)

\section{Therapeutic outcomes of ESD of undifferentiated-type EGC}

Endoscopic resections for EGD were divided into two types of procedures, endoscopic mucosal resection (EMR) and endoscopic submucosal dissection (ESD). There are several EMR procedures, including the strip biopsy method (Okazaki Y et al.,1991), double channel method (Takekoshi T et al.,1986), EMR-cap method (Takeshita et al.,1997) These EMR 
procedures, however, cannot be used for the en bloc resection of lesions larger than $2 \mathrm{~cm}$. (Hyun DH et al.,2003)

On the other hand, ESD techniques can make en bloc resection of large lesions or ulcerated lesions feasible. It is important for the success of the ER of undifferentiated-type EGC that the histological findings are evaluated in detail. If the lesion is non-curative pathologically, the patient must undergo additional surgical resection of the stomach. Therefore, ER of undifferentiated-type EGC should be performed with an en bloc resection by ESD procedure.

We reviewed 58 patients with preoperatively diagnosed undifferentiated-type EGC (expanded-indication lesion) who underwent ESD at the Cancer Institute Hospital between September 2003 and August 2008. 9 We carried out ESD using the insulationtipped diathemic knife method, and glycerol or hyaluronic acid as the local injection material.

The therapeutic outcomes of ESD are shown in Table 4.

The mean diameter of resected specimens was 30 $\mathrm{mm}$ (range, 15-48mm), the mean diameter of lesions was $11 \mathrm{~mm}$ (range, 2-28mm), the median operation time was $70 \mathrm{~min}$ (range, 23-340 min), the en bloc resection rate was $98 \%$ (57/58 patients), the complete en bloc resection (R0 resection) rate was $90 \%$ (52/58 patients), the curative resection rate was $79 \%(46 / 58$ patients).

Bleeding complications occurred in five cases $(8.6 \%)$. No cases required blood transfusion or surgery. Perforation occurred in two cases $(3.4 \%)$, both of which were conservatively and successfully treated by clipping closure. The mean hospital stay was 6.7 days (range, 4-14 days)

\begin{tabular}{ll}
\hline Specimen diameter (mm), mean (range) & $30(15-48)$ \\
Tumor diameter (mm), mean (range) & $11(2-28)$ \\
Operation time (minutes), median (range) & $70(23-340)$ \\
One-piece resection rate, $\mathrm{n} / \mathrm{N}(\%)$ & $57 / 58(98 \%)$ \\
Complete resection rate, $\mathrm{n} / \mathrm{N}(\%)$ & $52 / 58(90 \%)$ \\
Curative resection rate, $\mathrm{n} / \mathrm{N}(\%)$ & $46 / 58(79 \%)$ \\
Accurate preoperative diagnosis, $\mathrm{n} / \mathrm{N}(\%)$ & $47 / 58(81 \%)$ \\
Complications, $\mathrm{n}(\%)$ & \\
Bleeding & $5(8.6 \%)$ \\
Perforation & $2(3.4 \%)$ \\
Hospital stay (days), mean (range) & $6.7(4-14)$ \\
\hline
\end{tabular}

ESD: Endoscopic submucosal dissection

EGC: Early gastric cancer

Table 4. ESD for undifferentiated-type EGC treatment results $(\mathrm{N}=58)$

Pathological examination revealed that expanded-indication lesions were present in 47 cases and non-indication lesions in 11. The therapeutic outcomes were compared between the two groups, as shown in Table 5. 


\begin{tabular}{|c|c|c|c|}
\hline & Expanded-indication lesions $(\mathrm{N}=47)$ & Non-indication lesions $(\mathrm{N}=11)$ & $P$ value \\
\hline Specimen diameter (mm), mean (range) & $29(15-48)$ & $33(15-45)$ & 0.2 \\
\hline Tumor diameter (mm), mean (range) & $8.9(2-18)$ & $18(8-28)$ & $<0.01$ \\
\hline $\begin{array}{l}\text { Operation time (minutes), median } \\
\text { (range) }\end{array}$ & $65(23-340)$ & $80(26-250)$ & 0.55 \\
\hline One-piece resection rate, $\mathrm{n} / \mathrm{N}(\%)$ & $47 / 47(100 \%)$ & $10 / 11(91 \%)$ & 0.42 \\
\hline Complete resection rate, $\mathrm{n} / \mathrm{N}(\%)$ & $46 / 47(98 \%)$ & $6 / 11(55 \%)$ & $<0.01$ \\
\hline Curative resection rate, $\mathrm{n} / \mathrm{N}(\%)$ & $46 / 47(98 \%)$ & $0 / 11(0 \%)$ & \\
\hline \multicolumn{4}{|l|}{ Complications, $\mathrm{n}(\%)$} \\
\hline Bleeding & $5(11 \%)$ & 0 & 0.59 \\
\hline Perforation & $2(4.3 \%)$ & 0 & 0.82 \\
\hline Hospital stay (days), mean (range) & $6.6(4-14)$ & $7.2(5-9)$ & 0.3 \\
\hline
\end{tabular}

Table 5. ESD for undifferentiated type EGC treatment results by lesion group $(\mathrm{N}=58)$

With the limited expanded-indication lesions, the mean diameter of the resected specimens was $29 \mathrm{~mm}$ (range, $15-48 \mathrm{~mm}$ ), the mean diameter of lesions was $8.9 \mathrm{~mm}$ (range, $2-18 \mathrm{~mm}$ ), the median operation time was $65 \mathrm{~min}$ (range, 23-340 $\mathrm{min}$ ), the en bloc resection rate was $100 \%$ (47/47 patients), the complete en bloc resection rate was $98 \%$ (46/47 patients), and the curative resection rate was $98 \%$ (46/47 patients).

From these results, it can be seen that ESD of expanded-indication lesions for undifferentiated-type EGC was associated with good therapeutic outcomes.

However, non-curative resection was pathologically identified in 12 (21\%) of the 58 patients. Eleven of the 12 non-curative resection cases had non-indication lesions. The reasons for incurability were the presence of submucosal invasion in seven cases (12\% of 58 patients), tumor diameter of $21 \mathrm{~mm}$ or more in five $(8.6 \%)$, and the presence of ulcer scarring in two (3.4\%); some cases had more than one reason.

The most common factor responsible for non-curative resection was incorrect diagnosis of the depth of invasion. (Table 6)

\begin{tabular}{lc}
\hline Factors & $\mathrm{n}(\%) \dagger$ \\
\hline Submucosal invasion & $7(12 \%)$ \\
Tumor diameter $>20 \mathrm{~mm}$ & $5(8.6 \%)$ \\
Ulcer findings & $2(3.4 \%)$ \\
Lymphatic-vascular involvement & $2(3.4 \%)$ \\
\hline
\end{tabular}

*Some patients had more than one causative factor.

$\dagger$ Percentages were calculated based on overall population $(\mathrm{N}=58)$.

Table 6. Factors responsible for non-curative resection of non-indication lesions $(\mathrm{N}=11)^{*}$

Six of the seven patients who were found to have submucosal invasion had undergone EUS that resulted in a diagnosis of intramucosal carcinoma. 
It has been reported previously that EUS correctly diagnosed the depth of invasion of EGC in $64-78 \%$ of cases, and the correct diagnosis rate was lower in cases of undifferentiated-type compared to differentiated-type. (Akahoshi K et al.,1998; Hizawa K et al.,2002) Although more accurate diagnosis of the invasive depth is necessary, the currently available assessment methods have limitations in their precision. (Kim JH et al.,2007)

In terms of the technological aspects of ESD, resectable expanded-indication lesions of undifferentiated-type EGC are less than $20 \mathrm{~mm}$ in diameter and have no ulceration, the ESD procedures are easier than for lesions with diameters greater than $20 \mathrm{~mm}$ or for ulcerated differentiated-type EGC. Therefore, we consider that the ideal method for diagnosing the invasion depth might be to first carry out ESD followed by pathological examination of resected specimens.

However, if this diagnostic ESD determines that a tumor diameter exceeds $20 \mathrm{~mm}$, it is probable that ESD will result in non-curative resection, so more precise preoperative diagnosis of the lesion area using circumferential biopsies is essential.

\section{Conclusion}

Endoscopic resection of differentiated-type EGC is now standard treatment not only in Japan but also in other parts of the world. Undifferentiated-type EGC has a high rate of lymph node metastasis compared with differentiated-type EGC, and endoscopic resection of undifferentiated-type EGC remains controversial.

However, if the tumor is detected at an early stage and meets the criteria for expandedindication lesion of undifferentiated-type EGC, then the lymph node metastasis is very rare. We propose that endoscopic resection should be performed on such lesions to avoid unnecessary invasive surgery and optimize the quality of life. In this review, we have described our therapeutic outcomes of endoscopic resection for undifferentiated-type EGC.

An interesting result amongst our cases was the observation that some patients who were $\mathrm{H}$. pylori negative had undifferentiated-type EGC. The rate of $\mathrm{H}$. pylori infection is predicted to decrease in the future. We should take care in the management of cases of undifferentiated-type EGC without $\mathrm{H}$. pylori infection.

It is necessary to study further cases, with a longer follow up period, to prove the validity of the concept of endoscopic resection of undifferentiated-EGC which we have proposed here. We hope that multicenter, prospective studies will be carried out to asses further this expanded-indication for ER of undifferentiated-type EGC.

\section{References}

Abe N, Watanabe T, Sugiyama M, et al. (2004), Endoscopic treatment or surgery for undifferentiated early gastric cancer? Am J Surg, 188,2,181-4.

Akahoshi K, Chijiwa Y, Hamada S, et al. (1998), Pretreatment staging of endoscopically early gastric cancer with a $15 \mathrm{MHz}$ ultrasound catheter probe. Gastrointest Endosc,48, 5, 470-6.

Fujii T, Yoshida S, Abe K, et al. (1994), "Very well differentiated tubular adenocarcinoma" of the stomach: its endoscopic and histopathological characteristics. Jpn J Clin Oncol, 24, 3, 128-34.

Gono K, Obi T, Yamaguchi M, et al. (2004), Appearance of enhanced tissue features in narrow-band endoscopic imaging. J Biomed Opt, 9, 3, 568-77. 
Gotoda T, Yamamoto H, Soetikno RM. (2006). Endoscopic submucosal dissection of early gastric cancer. J Gastroenterol,41,10, 929-42.

Gotoda T, Yanagisawa A, Sasako M, et al. (2000). Incidence of lymph node metastasis from early gastric cancer: estimation with a large number of cases at two large centers. Gastric Cancer. 2000, 3, 4, 219-25.

Ha TK, An JY, Youn HK et al. (2008), Indication for endoscopic mucosal resection in early signet ring cell gastric cancer. Ann Surg Oncol, 15, 2, 508-13.

Hirasawa T, Gotoda T, Miyata S, et al. (2009), Incidence of lymph node metastasis and the feasibility of endoscopic resection for undifferentiated-type early gastric cancer. Gastric Cancer, 12, 3, 148-52.

Hizawa K, Iwai K, Esaki M et al. (2002), Is endoscopic ultrasonography indispensable in assessing the appropriateness of endoscopic resection for gastric cancer? Endoscopy, $34,12,973-8$.

Hyun DH, Jeong S, Lee JW, et al. (2003), Usefulness of endoscopic mucosal resection for curative treatment of early gastric cancer. Korean J Gastroenterol, 42, 6, 453-60.

Kang HY, Kim SG, Kim JS et al. (2010), Clinical outcomes of endoscopic submucosal dissection for undifferentiated early gastric cancer. Surg Endosc, 24, 3, 509-16.

Kim JH, Lee YC, Kim H, et al. (2009), Endoscopic resection for undifferentiated early gastric cancer. Gastrointest Endosc, 69, 4, 1-9.

Kim JH, Song KS, Youn YH, et al. (2007), Clinicopathologic factors influence accurate endosonographic assessment for early gastric cancer. Gastrointest Endosc , 66, 5, 9018.

Kunisaki C, Takahashi M, Nagahori Y, et al.(2009), Risk factors for lymph node metastasis in histologically poorly differentiated type early gastric cancer. Endoscopy, 41, 6, 498503.

Lehnert T, Erlandson RA, Decosse JJ. (1985), Lymph and blood capillaries of the human gastric mucosa. A morphologic basis for metastasis in early gastric carcinoma. Gastroenterology, 89, 5, 939-50.

Li C, Kim S, Lai JF, et al. (2008), Risk factors for lymph node metastasis in undifferentiated early gastric cancer. Ann Surg Oncol, 15, 3, 764-9.

$\mathrm{Li} \mathrm{H}, \mathrm{Lu} \mathrm{P}, \mathrm{Lu} \mathrm{Y}$, et al. (2008), Predictive factors for lymph node metastasis in poorly differentiated early gastric cancer and their impact on the surgical strategy. World $J$ Gastroenterol, 14, 26, 4222-6.

Li H, Lu P, Lu Y, et al. Predictive factors of lymph node metastasis in undifferentiated early gastric cancers and application of endoscopic mucosal resection. Surg Oncol, 19, 4, 221-6

Listrom MB, Fenoglio-Preiser CM. (1987), Lymphatic distribution of the stomach in normal, inflammatory, hyperplastic, and neoplastic tissue. Gastroenterology, 93, 3, 506-14.

Miyata M, Yokoyama Y, Okoyama N, et al. (2000). What are the appropriate indication for endoscopic mucosal resection for early gastric cancer? Analysis of 256 endoscopically resected lesions. Endoscopy, 32, 10, 773-778.

Nakayoshi T, Tajiri H, Matsuda K et al. (2004), Magnifying endoscopy combined with narrow band imaging system for early gastric cancer: correlation of vascular pattern with histopathology (including video). Endoscopy, 36, 12, 1080-4.

Nasu J, Nishina T, Hirasaki S, et al. (2006), Predictive factors of lymph node metastasis in patients with undifferentiated early gastric cancers. J Clin Gastroenterol, 40, 5, 412-5. 
Ninomiya Y, Yanagisawa A, Kato Y, et al. (2000). Unrecognizable intramucosal spread of diffuse-type mucosal gastric carcinomas of less than $20 \mathrm{~mm}$ in size. Endoscopy, 32, 8, 604-8.

Oohara T, Aono G, Ukawa S, et al. (1984), Clinical diagnosis of minute gastric cancer less than $5 \mathrm{~mm}$ in diameter. Cancer, 53, 1, 162-5.

Okazaki Y, Tada M. (1991), Endoscopic treatment of early gastric cancer. Semin Surg Oncol, $7,6,351-5$.

Park YD, Chung YJ, Chung HY, et al. (2008), Factors related to lymph node metastasis and the feasibility of endoscopic mucosal resection for treating poorly differentiated adenocarcinoma of the stomach. Endoscopy, 40, 1, 7-10.

Sako A, Kitayama J, Ishikawa M et al. (2006), Impact of immunohistochemically identified lymphatic invasion on nodal metastasis in early gastric cancer. Gastric Cancer, 9, 4, 295-302.

Sano T, Kobori O, Muto T. (1992). Lymph node metastasis from early gastric cancer: endoscopic resection of tumour. Br J Surg, 79, 3, 241-4.

Sawada S, Fujisaki J, Yamamoto N, et al. (2010), Expansion of indications for endoscopic treatment of undifferentiated mucosal gastric cancer: analysis of intramucosal spread in resected specimens. Dig Dis Sci, 55, 5, 1376-80.

Takahashi H, et al. (2009), Endoscopic Diagnosis of Early Small and Minute Gastric Cancer. Gastrointestinal Cancer Atras for Endoscopic Therapy. Springer, Tokyo, 21-30.

Takekoshi T, Takagi K, Fujii A et al. (1986), Treatment of early gastric cancer by endoscopic double snare polypectomy (EDSP). Gan No Rinsho. 32, 10, 1185-90.

Takeshita K, Tani M, Inoue H, et al. (1997), A new method of endoscopic mucosal resection of neoplastic lesions in the stomach: its technical features and results. Hepatogastroenterology, 44, 18, 1602-11.

Yamao T, Shirao K, Ono H, et al. (1996). Risk factors for lymph node metastasis from intramucosal gastric carcinoma. Cancer. 1996, 77, 4, 602-6.

Yamamoto Y, Fujisaki J, Hirasawa T, et al. (2010), Therapeutic outcomes of endoscopic submucosal dissection of undifferentiated-type intramucosal gastric cancer without ulceration and preoperatively diagnosed as 20 millimetres or less in diameter. Dig Endosc, 22, 2, 112-8.

Ye BD, Kim SG, Lee JY, et al. (2008), Predictive factors for lymph node metastasis and endoscopic treatment strategies for undifferentiated early gastric cancer. $J$ Gastroenterol Hepatol, 23, 1, 46-50. 


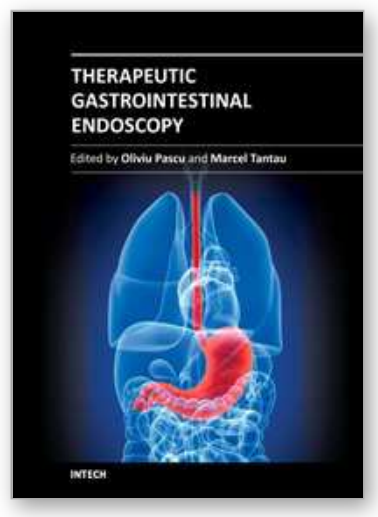

\author{
Therapeutic Gastrointestinal Endoscopy \\ Edited by Prof. Oliviu Pascu
}

ISBN 978-953-307-743-7

Hard cover, 216 pages

Publisher InTech

Published online 22, September, 2011

Published in print edition September, 2011

Endoscopy has had a big role in the development of modern gastroenterology. Modern endoscopy will certainly be more therapeutic. It started with endoscopic hemostasis and polipectomy, than beginning of the 1970 's with the advent of endoscopic sphincterotomy extended to biliopancreatic pathology and has a huge impact in this difficult pathology. Plastic stents made the first steps in endoscopic palliation of neoplastic jaundice, metallic stents, covered or uncovered are better for biliary palliation and can be used also for palliation neoplastic obstruction at different levels of the digestive tube. Resection of digestive tumors has evolved now to sub-mucosal resection, looking to have one-piece complete resection. Interventional endoscopy is now very complex and takes a lot of time for endoscopists to learn properly these techniques. This book is a very good up-to-date overview of new techniques of interventional endoscopy for those who want to learn or develop their knowledges in this field.

\title{
How to reference
}

In order to correctly reference this scholarly work, feel free to copy and paste the following:

Yorimasa Yamamoto, Junko Fujisaki, Toshiaki Hirasawa, Takanori Suganuma, Masami Omae, Kazuhisa Okada, Susumu Sawada, Akiyoshi Ishiyama, Tomohiro Tuchida, Etuo Hoshino, Hiroshi Takahashi and Masahiro Igarashi (2011). Endoscopic Resection for Undifferentiated-Type Early Gastric Cancer, Therapeutic Gastrointestinal Endoscopy, Prof. Oliviu Pascu (Ed.), ISBN: 978-953-307-743-7, InTech, Available from: http://www.intechopen.com/books/therapeutic-gastrointestinal-endoscopy/endoscopic-resection-forundifferentiated-type-early-gastric-cancer1

\section{INTECH}

open science | open minds

\section{InTech Europe}

University Campus STeP Ri

Slavka Krautzeka 83/A

51000 Rijeka, Croatia

Phone: +385 (51) 770447

Fax: +385 (51) 686166

www.intechopen.com

\section{InTech China}

Unit 405, Office Block, Hotel Equatorial Shanghai

No.65, Yan An Road (West), Shanghai, 200040, China 中国上海市延安西路65号上海国际贵都大饭店办公楼 405 单元

Phone: +86-21-62489820

Fax: $+86-21-62489821$ 
(C) 2011 The Author(s). Licensee IntechOpen. This chapter is distributed under the terms of the Creative Commons Attribution-NonCommercialShareAlike-3.0 License, which permits use, distribution and reproduction for non-commercial purposes, provided the original is properly cited and derivative works building on this content are distributed under the same license. 